\title{
Impregnation of polyurethane foam with activated carbon for enhancing oil removal from water
}

\author{
A. Keshavarz ${ }^{1}$ - H. Zilouei ${ }^{1}$ A. Abdolmaleki ${ }^{2}$ A. Asadinezhad ${ }^{1} \cdot$ A. A. Nikkhah ${ }^{1}$
}

Received: 8 April 2015/Revised: 13 September 2015/Accepted: 11 November 2015/Published online: 16 December 2015

(C) Islamic Azad University (IAU) 2015

\begin{abstract}
To enhance the oil sorption capacity of polyurethane foam, different amounts of activated carbon (0.5, 1,2 and $3 \mathrm{wt} \%$ ) were grafted onto the surface of polyurethane foam. The modified polyurethane foam was characterized by Fourier transform infrared spectroscopy, scanning electron microscopy, thermogravimetric analysis and tensile elongation test. Grafting of activated carbon improved the polyurethane foam toughness and thermal resistance as revealed by tensile elongation and thermogravimetric tests, respectively. Experimental results showed the enhancement of oil sorption capacity and reduction in the water sorption in all cases. The optimal amount of activated carbon on the surface was $1 \mathrm{wt} \%$ which enhanced the oil sorption capacity up to $33.2 \%$. Reusability feature of the optimum sorbent was examined through four cycles of chemical regeneration, and about $85 \%$ of the initial sorption capacity of the modified polyurethane foam was remained at the end. Equilibrium isotherms were analyzed using Langmuir, Freundlich and Redlich-Peterson isotherms using linear and nonlinear regression methods. The Marquardt's percent standard deviation and hybrid fractional error functions were minimized and normalized to investigate the effect of error criteria to determine the parameters of isotherms. The nonlinear method was found to be more accurate to determine the isotherm parameters, and the Langmuir isotherm was the best-fitting model.
\end{abstract}

H. Zilouei

hzilouei@cc.iut.ac.ir

1 Department of Chemical Engineering, Isfahan University of Technology, Isfahan 84156-83111, Iran

2 Department of Chemistry, Isfahan University of Technology, Isfahan 84156-83111, Iran
Keywords Adsorbent · Isotherm · Oil pollution · Reusability $\cdot$ Surface modification

\section{Introduction}

Water pollution by oil as a result of oil release during transportation and storage has raised grave worldwide concerns (Adebajo et al. 2003). About 5 million tons of oil is transported yearly overseas by tankers posing risk of oil spillage or leakage to the marine ecosystem. Oil spill adversely affects the diverse marine species, the seaside plants and animal such as fish, birds and mollusks (AlMajed et al. 2012; Aguilera et al. 2010). Moreover, human is exposed to potential health problem as the sea foods can carry oil pollutants and cause genotoxic damage in consumers (Aguilera et al. 2010). As the spilled oil undergoes several processes such as spreading, evaporation, dissolution, biodegradation and emulsification, developing effective methods for the quick removal of oil from the polluted environment is essential (Banerjee et al. 2006; Annunciado et al. 2005). Methods of oil spill removal can be classified into three main groups: oil separation and collection from water surface, mixing oil and water by dispersants and in situ burning (Avila et al. 2014).

Among the oil removal methods, using sorbents is of great interest from the economical and ecological point of view (Sidik et al. 2012). Adding the sorbent material to an oil spill area forms a semisolid phase which eases the oil removal through sorption (Teas et al. 2001). Selectivity, high adsorption capacity, fast adsorption kinetics, easy regeneration and reusability, good mechanical strength, low cost and biodegradability are ideal requirements of a commercial sorbent (Teas et al. 2001). Inorganic mineral sorbents such as graphite have showed good oil sorption; 
however, their shortcomings such as oil release, sinking to the water and high cost have made them inappropriate choice for oil removal in large scale (Tryba et al. 2003). Organic vegetable products such as cotton are cheap, biodegradable and easily available, but their low sorption capacity besides high total cost of removal process has made them unfavorable choice for oil sorption (Said et al. 2009). Synthetic organic products such as polyurethane and polypropylene foam have good oleophilic properties. However, the main disadvantage of this group is nonbiodegradability (Al-Majed et al. 2012).

Polyurethane foam (PUF) and activated carbon (AC) are among the widely used sorbent for oily water treatment. PUF is commercially produced, has shown good oil sorption capacity and is reusable ( $\mathrm{Wu}$ et al. 2014; $\mathrm{Li}$ et al. 2012). Surface modification of PUF can be an effective method to improve the hydrophobic and oleophilic properties of this sorbent without changing the bulk properties. Wu et al. (2014) for developing polyurethane sponges with hydrophobic surface treated the PUF samples with $\mathrm{SiO}_{2}$ sol and improved the sorption of motor oil from water. Li et al. (2012) improved the oleophilic properties of PUF by grafting lauryl methacrylate to the surface of PUF which increased the sorption of kerosene.

Activated carbon is widely used as sorbent for wastewater treatment due to its high surface area ranging from 500 to $1500 \mathrm{~m}^{2} \mathrm{~g}^{-1}$, the presence of different functional groups on its surface, well-developed internal microporous structure and hydrophobic internal surface (Yin et al. 2007; Marsh and Reinoso 2006). It is a common effective sorbent for the removal of organic and inorganic contaminants from water (Rivera-Utrilla et al. 2011; Okiel et al. 2011). The unique adsorption properties of $\mathrm{AC}$ are mainly attributed to lactones and quinones functional groups (Bhatnagar et al. 2013). However, AC application is limited because of its poor mechanical strength and sorption selectivity and incomplete regeneration (Zhou et al. 2008). In recent years, intense researches have been performed to improve the AC selectivity for adsorbing specific contaminates by improving the carbon surface through different chemical, physical and biological methods (Bhatnagar et al. 2013). The number of acidic functional groups on the AC surface is related to uptake of organic contaminants (Emam 2013). The acidic character of AC is attributed to oxygen containing surface groups (i.e., carboxyl, carbonyl and phenols) on the outer surface or edge of the basal AC plane (Shafeeyan et al. 2010). Emam (2013) investigated the effect of AC acidic treatment on oil sorption from water at $\mathrm{pH} 7$, which oil sorption was increased up to $12 \mathrm{mg}$ in comparison with untreated AC.

The main purpose of this study is to modify the surface of PUF with impregnation of AC in order to increase the oil sorption capacity of the PUF. Then, the performance of surface-modified PUF is determined in terms of oil sorption capacity, sorption efficiency and reusability. This study was performed in a 12-month period between December 2013 and December 2014 at Isfahan University of Technology, Iran.

\section{Materials and methods}

\section{Materials}

Activated carbon (AC) with acidic $\mathrm{pH}$ and particle size under $100 \mu \mathrm{m}$ was obtained from Merck Company (Germany). 1,1-Dichloro-1-fluoroethane (HCFC 141b) was purchased from Lin'an E-COOL Refrigeration Equipment CO (China). NIXOL AM-313 polyether polyol was obtained from KPX Chemical CO (South Korea), and methylene diphenyl diisocyanate (MDI) was obtained from Daeyang International CO (South Korea). Light crude oil was obtained from Isfahan refinery feed stream (Iran). Industrial grade xylene was purchased from Isfahan petrochemical complex (Iran). Petroleum ether (boiling range of $30-60{ }^{\circ} \mathrm{C}$ ) was purchased from Pars Chemie Co (Iran).

\section{Synthesis of polyurethane foam}

To synthesize the open-cell polyurethane foam (PUF), deionized water and HCFC $141 \mathrm{~b}$ were used as the chemical and physical blowing agents, respectively. At first, at ambient temperature $\left(23 \pm 2{ }^{\circ} \mathrm{C}\right), 10 \mathrm{~g}$ of polyol was completely mixed with $0.1 \mathrm{~g}$ of deionized water and $1.5 \mathrm{~g}$ of HCFC $141 \mathrm{~b}$. Once the mixing was complete, $4 \mathrm{~g}$ of MDI was added to the prepared mixture and again was mixed by use of a mixer at $1000 \mathrm{rpm}$. Finally, the mixture was left for $1 \mathrm{~h}$ to provide enough time for the foaming reaction.

\section{Impregnation of polyurethane foam with activated carbon}

Impregnation of PUF was done by utilizing the reaction between carboxylic and phenolic $\mathrm{OH}$ agents on the surface of $\mathrm{AC}$ and $\mathrm{OH}$ agents in the foam structure. The reaction schematically presented in Fig. 1 was done by MDI in which one MDI tail reacted with $\mathrm{OH}$ groups on the surface of $\mathrm{AC}$ and the other reacted with the $\mathrm{OH}$ agents existing in the polyether polyol chains. Samples with $0.5,1,2$ and $3 \mathrm{wt} \%$ of AC on the PUF surface were prepared. At first, $300 \mathrm{~mL}$ petroleum ether was poured in a glass beaker, and then, 10 times more than the final weight of $\mathrm{AC}$ on the surface was added to the beaker and was stirred for $5 \mathrm{~min}$ at $1000 \mathrm{rpm}$. Then, $1 \mathrm{~g}$ of PUF cubes was added and was stirred for $15 \mathrm{~min}$ to let the $\mathrm{AC}$ particles penetrate into the foam pores. After that, while still mixing, as much as two 
<smiles>O=C(Nc1ccc(Cc2ccc([N+](=O)[O-])cc2)cc1)OCCOCCOCCOC(=O)C(=O)O</smiles><smiles>CC(C)(C)CCCCOC(=O)NC(=O)OC(=O)Nc1ccc(Cc2ccc(NC(=O)OCCOCCOC(=O)Nc3ccc(Cc4ccc(N=O)cc4)cc3)cc2)cc1</smiles>

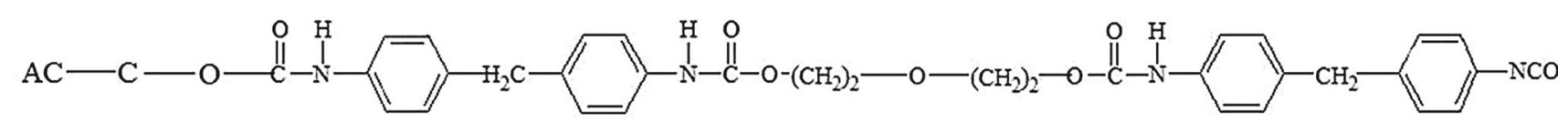

\section{AC: Activated Carbon}

Fig. 1 Schematic of the reaction between MDI and $\mathrm{OH}$ groups

times the weight of the added AC, MDI was added to the reaction environment drop by drop and was stirred for $40 \mathrm{~min}$. The cubes were taken out and dried in an oven at $100{ }^{\circ} \mathrm{C}$ for $10 \mathrm{~min}$. Then, again, the cubes were washed by petroleum ether, to remove the particles that have just been trapped in the pores without reaction with the surface, and were dried in oven at $100{ }^{\circ} \mathrm{C}$ for $30 \mathrm{~min}$. Finally, the dried cubes were scaled, and their weight in comparison with the blank cubes weight showed the weight of the added AC to the surface. The samples with over $\pm 10 \mathrm{wt} \%$ deviation from the mean were excluded.

\section{Sorption capacity experiment}

Light crude oil was used to study the sorption capacity of the prepared sorbents. The sorption experiments were conducted based on the Standard Test Method for Sorbent Performance of Adsorbents (ASTMF726-99).

All the experiments were conducted in water-oil system. To do this, $250 \mathrm{~mL}$ of water was poured into a $600 \mathrm{~mL}$ beaker and then crude oil was added to the water so that at least a layer with thickness $2-4 \mathrm{~mm}$ was formed on the water surface. Then, $1.0 \mathrm{~g}$ surface-modified sorbent was added to the beaker which was placed on a shaker table with frequency $150 \mathrm{rpm}$ for $15 \mathrm{~min}$. The content of the beaker was allowed to settle for 2 min after shaking. Then, the sorbent cubes were removed from the system by a forceps and allowed to drain for $30 \pm 3 \mathrm{~s}$ and were weighed. After that, the oily cubes were fully washed with industrial grade xylene to extract the adsorbed oil and water. The final extracted solution was used to determine the weight of the water trapped in the oil based on the Standard Test Method for Water in Crude Oil by Distillation (ASTMD4006-81). The extracted solution was poured into a 1000-mL round-bottom, glass distillation flask which was connected to a 400-mm Liebig condenser and a $10-\mathrm{mL}$ water trap. The extracted solution in the flask was heated. After initial heating, boiling rate was adjusted so that the condensate passed not longer than three quarters of the condenser inner tube length and distillate was discharged into the trap at the approximately 2-5 drops per second rate. Distillation was continued until the volume of the water in the trap remained constant and no water was visible in the other part of the apparatus. When the distillation operation was complete, the trap content was allowed to cool down to $20{ }^{\circ} \mathrm{C}$. Finally, the collected water in the trap was weighed. The experiments were conducted in triplicate. If the value of any obtained result $(\mathrm{g} / \mathrm{g})$ deviated beyond $15 \%$ of the mean, then the samples would be excluded.

The oil sorption capacity of the sorbents was calculated by following relation:

$M=\frac{m_{\mathrm{s}}-m_{\mathrm{w}}-m_{0}}{m_{0}}$

where $M$ is the oil sorption capacity $(\mathrm{g} / \mathrm{g}), m_{\mathrm{s}}$ is the weight of saturated sorbent (weight of the water plus oil and sorbent), $m_{\mathrm{w}}$ is the weight of adsorbed water $(\mathrm{g})$ and $m_{0}$ is the initial dry weight of sorbent (g). Oil removal percentage was determined by:

$P_{\mathrm{r}}=\frac{m_{\mathrm{o}}}{m_{i}} \times 100$

where $P_{\mathrm{r}}$ is the oil removal percentage, $m_{\mathrm{o}}$ is the weight of removed oil $(\mathrm{g})$ and $m_{i}$ is the initial weight of oil $(\mathrm{g})$. Oil sorption efficiency of the sorbent is defined as the ratio of adsorbed oil weight to the total weight of adsorbed oil and water and is calculated by: 
$E=\frac{m_{\mathrm{o}}}{m_{\mathrm{o}}+m_{\mathrm{w}}} \times 100$

where $E$ is oil sorption efficiency, $m_{\mathrm{o}}$ is the weight of adsorbed oil $(\mathrm{g})$ and $m_{\mathrm{w}}$ is the weight of adsorbed water.

\section{Sorbent regeneration}

To identify the reusability feature of the developed sorbent, the sorbent cubes after the sorption experiments were chemically regenerated. The chemical method was done through washing the sorbent cubes with $150 \mathrm{~mL}$ fresh petroleum ether in a $250-\mathrm{mL}$ beaker for three times so that no color change was observed in the fresh washing petroleum ether at the third final stage. Then, the sorbent cubes were dried in an oven for $30 \mathrm{~min}$ at $100{ }^{\circ} \mathrm{C}$.

\section{Sorbent Characterization}

The presence of the AC particles on the surface of PUF was explored by scanning electron microscopy (SEM) (TESCAN_VEGA3, SBU-Easy Probe, Czech). FTIR spectra of blank PU and AC surface-modified PUF cubes were obtained by FTIR spectrometer (JASCO, Model 6300, Japan). In this study, FTIR technique was used to ensure the presence of the carboxylic acids and phenol on the AC surface, the PU synthesis confirmation and also to validate the surface modification procedure through identifying created bond between AC and PUF. To study the effect of surface modification on thermal properties of the PUF, thermogravimetric analysis (TGA) was performed by a thermogravimetric analyzer (STA6000, PerkinElmer, USA). Tensile elongation test was performed to study the change in mechanical property of the developed sorbents by Zwick Universal Testing Machine 1446-60, Germany.

\section{Adsorption isotherms}

Equations of equilibrium isotherms were used to describe the experimental sorption data. The thermodynamic assumptions and parameters of the equations provide useful information about the sorption mechanism, the surface properties and affinities of the sorbent (Ho et al. 2005). In this study, the applicability of Langmuir, Freundlich and Redlich-Peterson isotherm models onto blank PUF and AC surface-modified PUF for oil removal from water was studied.

The linearization of nonlinear experimental data may distort the error distribution (Kumar et al. 2008). In addition, the linear analysis method is based on the assumption that the scatter of points around the line follows a Gaussian distribution and the error distribution is the same at every value of the equilibrium concentration (Ncibi 2008). Therefore, in selecting the optimum isotherm a comparison between the linear and nonlinear regression method was made to the experimental equilibrium data.

The linear regression analysis was done through the least square method, and the nonlinear regression was performed by use of the solver add-in function, Microsoft Excel, Microsoft Corporation, to directly estimate the model parameters from the nonlinear equations.

\section{Langmuir isotherm}

Langmuir model is based on the assumptions of a homogeneous surface with constant adsorption energy over the all sites, localized adsorption on the surface and monolayer a desorption (Limousin et al. 2007). The nonlinear and linear forms are represented as (Langmuir 1918):

$q_{\mathrm{e}}=\frac{q_{\mathrm{m}} K_{\mathrm{L}} C_{\mathrm{e}}}{1+K_{\mathrm{L}} C_{\mathrm{e}}}$

$\frac{C_{\mathrm{e}}}{q_{\mathrm{e}}}=\frac{C_{\mathrm{e}}}{q_{\mathrm{m}}}+\frac{1}{q_{\mathrm{m}} K_{\mathrm{L}}}$

where $q_{\mathrm{m}}\left(\mathrm{g} \mathrm{g}^{-1}\right)$ is the monolayer capacity of the adsorbent, $K_{\mathrm{L}}\left(\mathrm{L} \mathrm{g}^{-1}\right)$ is a constant related to the free energy of the adsorption and $C_{\mathrm{e}}$ and $q_{\mathrm{e}}$ are equilibrium concentration and the equilibrium oil concentration on the adsorbent, respectively. For the linear method, the isotherm constants $q_{\mathrm{m}}$ and $K_{\mathrm{L}}$ can be determined from the slope and intercept of the plot between $C_{\mathrm{e}} / q_{\mathrm{e}}$ and $C_{\mathrm{e}}$.

\section{Freundlich isotherm}

The Freundlich isotherm is an empirical equation that can be used for the systems on the assumption of heterogeneous sorption energy and interaction between the adsorbate molecules (Radhika and Palanivelu 2006). Freundlich isotherm model is not restricted to the monolayer adsorption and describes the non-ideal and reversible adsorption (Vasanth Kumar and Sivanesan 2006). The nonlinear and linear form of this model can be written as:

$q_{\mathrm{e}}=K_{\mathrm{F}} C_{\mathrm{e}}^{1 / n}$

where $K_{\mathrm{F}}\left(\mathrm{g} \mathrm{g}^{-1}\right)(\mathrm{L} / \mathrm{g})^{n}$ and $n$ are Freundlich constants related to the adsorption capacity and adsorption intensity, respectively. The $n$ parameter, known as the heterogeneity factor, can be used to indicate whether the adsorption is linear $(n=1)$, whether it is a chemical process $(n<1)$ or whether it is a physical process $(n>1)$ (Vargas et al. 2011). To determine the constants $K_{\mathrm{F}}$ and $n$, the linear form of the equation shown below may be used to plot the $\log \left(q_{\mathrm{e}}\right)$ against $\log \left(C_{\mathrm{e}}\right)$.

$\log q_{\mathrm{e}}=\frac{1}{\mathrm{n}} \log C_{\mathrm{e}}+\log K_{\mathrm{F}}$ 


\section{Redlich-Peterson isotherm}

Redlich-Peterson isotherm is a three-parameter isotherm model which includes the features of the Langmuir and Freundlich isotherm models (Hamdaoui and Naffrechoux 2007). Redlich-Peterson isotherm is written as:

$q_{\mathrm{e}}=\frac{K_{\mathrm{R}} C_{\mathrm{e}}}{1+a_{\mathrm{R}} C_{\mathrm{e}}^{\mathrm{g}}}$

where $K_{\mathrm{R}}\left(\mathrm{L}^{-1}\right)$ and $a_{\mathrm{R}}\left(L g_{\mathrm{R}}^{1-1 / K}\right)$ are Redlich-Peterson equation constants and $g$ is the exponent. When $g=1$, this isotherm is the same as Langmuir isotherm, and when $g=0$, the model is the same as Henry's equation. The linear form of Redlich-Peterson may be written as (Wu et al. 2010):

$\frac{C_{\mathrm{e}}}{q_{\mathrm{e}}}=\frac{1}{K_{\mathrm{R}}}+\frac{a_{\mathrm{R}}}{K_{\mathrm{R}}} C_{\mathrm{e}}^{g}$

Fitting the linear equation of Redlich-Peterson model was done through a trial and error procedure. The value of $g$ was assumed and substituted in the linear equation. Then, the regular least square regression was performed and the value of coefficient of determination $\left(R^{2}\right)$ was determined so that the value of $R^{2}$ became closer to one. The procedure continued until the difference between the values of the $R^{2}$ obtained from two respective iteration was less than $10^{-4}$.

\section{Estimation of the best-fitting isotherm model}

The coefficient of determination represents the variance and shows the goodness of the fit between the experimental data and isotherm model (Foo and Hameed 2010). However, the value of $R^{2}$ has no consideration for the degrees of freedom (number of the data minus the number of parameters) in ranking adsorption isotherm models. Other obvious issues with $R^{2}$ are sensitivity to extreme data points and the potential of being large in the case of models with more parameters (El-Khaiary and Malash 2011). Therefore, to avoid the pitfall of comparing the models with different number of parameters (Langmuir and Freundlich: two parameters and Redlich-Peterson: three parameters), using an index that considers the number of parameters is necessary. In the present study, to compare the models, the hybrid fractional error function (HYBRID) and Marquardt's percent standard deviation (MPSD) were used as error functions which are presented in Table 1.

In the case of nonlinear method, previous research studies showed that the predicted isotherms would vary with the error function used for the minimization of the error distribution between the experimental and predicted isotherms (Kumar et al. 2008). Therefore, to determine the parameters of the models and analyze the effect of the error function on the obtained results, HYBRID and MPSD were used in nonlinear regression to minimize the error distribution between the experimental data and the calculated data from the isotherm models.

As each of the error function is likely to produce a different set of isotherm parameters, an overall optimum parameter set is difficult to be identified directly. Hence, to determine the parameter set that best fit experimental results, the following procedure (so-called sum of the normalized errors, SNE) was performed for each set of parameters (Ho et al. 2002):

- Select one isotherm and one error function and compute the parameters of that isotherm by minimizing the selected error function.

- By using the determined parameters from the previous stage, compute the value of other error functions.

- Repeat last two stages for the rest of isotherm models and error functions.

- For each set of determined error values, normalize the numbers through dividing them by the maximum value of error in that set. Sum the normalized values.

- The parameter sets with the lowest value of SNE are accepted as the best.

\section{Results and discussion}

\section{FTIR}

The FTIR spectra of blank PU, AC and surface-modified PUF are presented in Fig. 2. As for the blank PUF, the peak

Table 1 List of the error functions

\begin{tabular}{lll}
\hline Error function & Definition/expression & References \\
\hline Coefficient of determination $\left(R^{2}\right)$ & $\frac{\sum_{i=1}^{N}\left(q_{\mathrm{e}, \text { meas }}-\overline{q_{\mathrm{e} \text { calc }}}\right)_{i}^{2}}{\sum_{i=1}^{N}\left(q_{\mathrm{e}, \text { meas }}-\overline{\left.q_{\mathrm{e}, \text { calc }}\right)_{i}^{2}+\sum_{i=1}^{N}\left(q_{\mathrm{e}, \text { meas }}-q_{\mathrm{e}, \text { calc }}\right)_{i}^{2}}\right.}$ & Ho (2006) \\
Hybrid fractional error function (HYBRID) & $\frac{100}{N-P} \sum_{i=1}^{N}\left[\frac{\left(q_{\mathrm{e}, \text { meas }}-q_{\mathrm{e}, \text { calc }}\right)^{2}}{q_{\mathrm{e}, \text { meas }}}\right]_{i}$ & Ng et al. (2002) \\
Marquardt's percent standard deviation (MPSD) & $100 \sqrt{\frac{1}{N-P} \sum_{i=1}^{N}\left[\frac{\left(q_{\mathrm{e}, \text { meas }}-q_{\mathrm{e}, \text { alc }}\right)}{q_{\mathrm{e}, \text { meas }}}\right]_{i}^{2}}$ & Najafi et al. (2011) \\
\hline
\end{tabular}


Fig. 2 FTIR spectra of blank PUF and surface-modified PUF

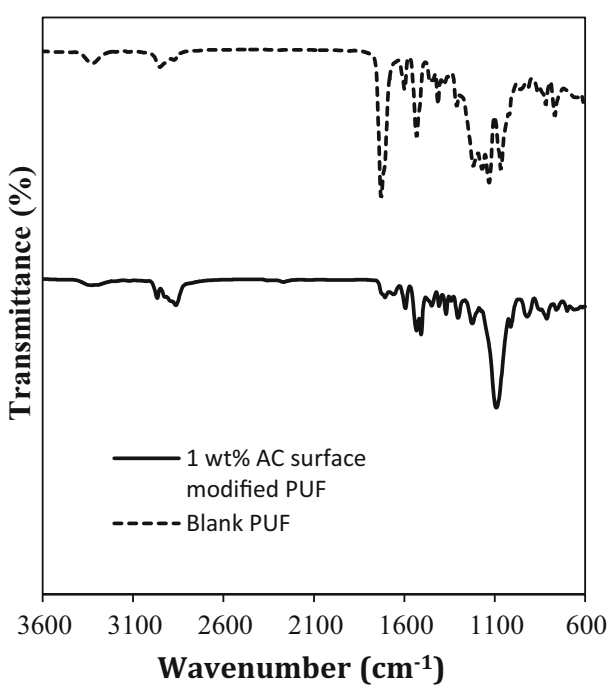

at $1070,3375 \mathrm{~cm}^{-1}$ and the strong peak at $1730 \mathrm{~cm}^{-1}$ are assigned to the etheric $\mathrm{C}-\mathrm{O}, \mathrm{N}-\mathrm{H}$ and $\mathrm{C}=\mathrm{O}$ stretching bands, respectively.

In the case of $\mathrm{AC}$, the presence of carboxylic acids and phenol on the AC surface is confirmed through the following observed peaks; the strong peak at $1745 \mathrm{~cm}^{-1}$ is assigned to $\mathrm{C}=\mathrm{O}$, the $\mathrm{O}-\mathrm{H}$ stretching vibration appears in the spectrum as a very broad signal within 3400-2400 $\mathrm{cm}^{-1}$ range and overlaps with the $\mathrm{C}-\mathrm{H}$ stretching band at $2925 \mathrm{~cm}^{-1}$, and the peak at $1240 \mathrm{~cm}^{-1}$ is assigned to the $\mathrm{C}-\mathrm{O}$ vibration. The broad peak at $3394 \mathrm{~cm}^{-1}$ and the weak peak at $1126 \mathrm{~cm}^{-1}$ are assigned to the phenolic $\mathrm{OH}$ and $\mathrm{C}-\mathrm{OH}$, respectively.

In the case of surface-modified PUF, except for the $\mathrm{C}=\mathrm{O}$ and $\mathrm{N}-\mathrm{H}$ groups, the observed peaks are almost the same as blank PUF. As it is observed, the $\mathrm{C}-\mathrm{O}$ peak at $1126 \mathrm{~cm}^{-1}$ and $\mathrm{N}-\mathrm{H}$ peak at $3357 \mathrm{~cm}^{-1}$ become weak and broad compared with those of blank PU. The weakness of the peaks reveals the occurrence of various interactions (like $\mathrm{H}$-bonding) and validates the presence of the $\mathrm{AC}$ on the surface of the polymer. The broadness is due to the heterogeneity of the carbonyl environments and validates the connection between the $\mathrm{AC}$ and the polymer. The strong peak at $1132 \mathrm{~cm}^{-1}$ is from the etheric $\mathrm{C}-\mathrm{O}$ stretching band. The peak at $1537 \mathrm{~cm}^{-1}$ is assigned to the aromatic rings.

\section{Tensile elongation}

The elongation test has been performed for the blank PUF and 0.5, 1 and $2 \mathrm{wt} \%$ AC surface-modified PUFs. The obtained results of $F_{\max }(\mathrm{N})$ and Elongation $(\mathrm{mm})$ are, respectively, reported as follows: $(4.99 \mathrm{~N}, 16.08 \mathrm{~mm}), \quad(5.71 \mathrm{~N}$, $14.15 \mathrm{~mm}),(6.18 \mathrm{~N}, 13.49 \mathrm{~mm}),(9.97 \mathrm{~N}, 13.27 \mathrm{~mm})$. Based on the results, it is clear that PUF toughness is improved by the presence of AC on the PUF surface, as in all samples, the elongation to break quantity decreases and the strength increases. Toughness improvement of the surface-modified PUF can be attributed to the strong interaction between AC particles and PUF which reduces the polymers chain mobility during mechanical deformation. It also confirms the good distribution of the AC particles on the foam surface.

\section{TGA}

The thermogravimetric curves of blank PUF and $1 \mathrm{wt} \%$ AC surface-modified PUF are shown in Fig. 3. The curves show higher char yield (at $780{ }^{\circ} \mathrm{C}$ ) and lower mass loss (29.47\% lower than blank PUF) for the surface-modified sample which shows the improvement of thermal resistance. The observed improvement can be explained based on the significant decrease in polymeric chains mobility as a result of the interaction between AC particles and PUF surface molecules. Such a reduction in molecular mobility along with the inherent tendency of AC particles to eliminate free radicals prevents polymer chains from thermal decomposition as revealed by TGA curves. The higher the chain mobility, the higher the probability of thermal degradation reactions will be. This fact has also been fully explained in the literature (Pal and Gautam 2013). Similar degradation pattern of the blank and surface-modified PUF indicates that the bulk structure of foam is not affected by the surface treatment (Alves et al. 2009).

\section{Oil adsorption capacity}

The experimental results of the sorption tests are presented in Table 2. As is seen, at each initial weight of oil, the oil removal percentage is increased in comparison with the blank PUF, and the amount of AC on the surface of PUF influences the sorbent oil removal performance. It is apparent that the PUF with $1 \mathrm{wt} \%$ of AC on the surface has the best performance and the maximum sorption is reached at $30 \mathrm{~g}$ 
Fig. 3 Thermogravimetric curves of blank PUF and $1 \mathrm{wt} \%$ AC surface-modified PUF

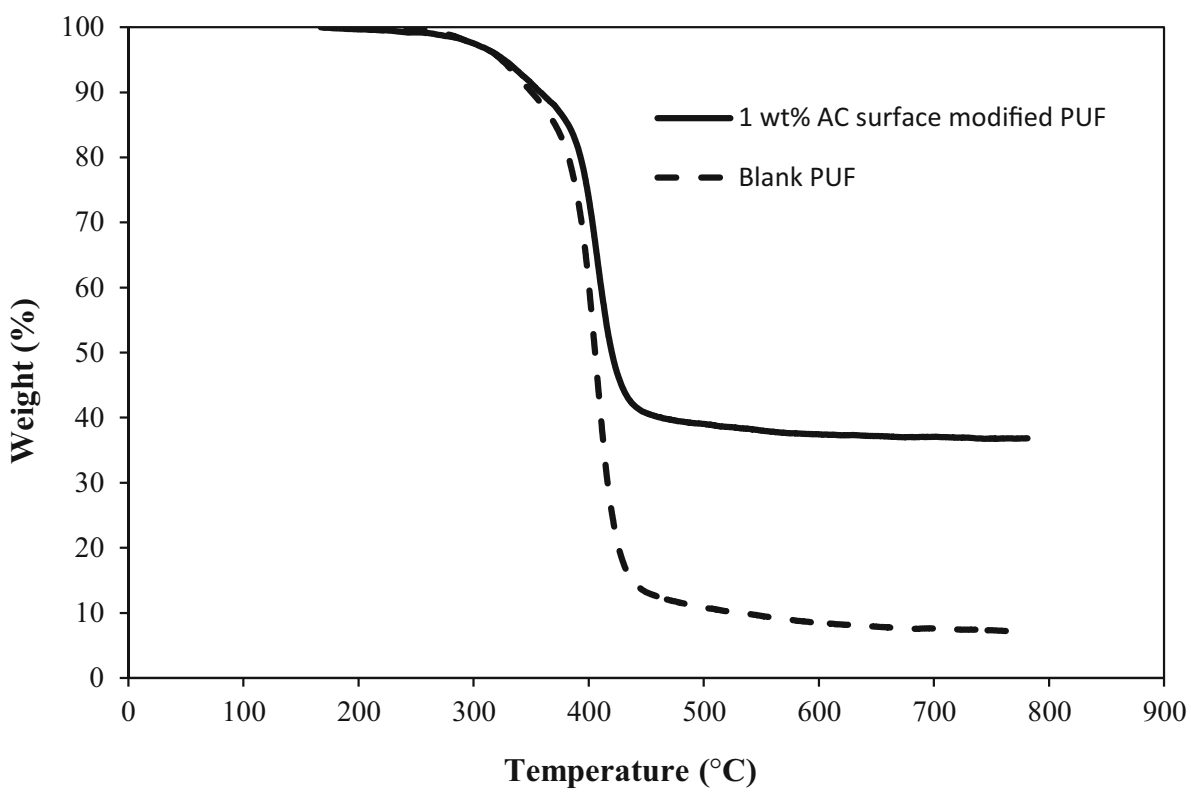

Table 2 Oil removal and efficiency percent of the prepared sorbent and their corresponding standard deviation $(\sigma)$

\begin{tabular}{|c|c|c|c|c|c|c|}
\hline \multirow{2}{*}{$\begin{array}{l}\text { Initial amount } \\
\text { of oil }(\mathrm{g})\end{array}$} & \multirow{2}{*}{$\begin{array}{l}\text { Sorbent removal and } \\
\text { efficiency percent }\end{array}$} & \multirow[t]{2}{*}{ Blank PUF } & \multicolumn{4}{|c|}{ AC surface-modified PUF } \\
\hline & & & $0.5 \mathrm{wt} \%$ & $1 \mathrm{wt} \%$ & $2 \mathrm{wt} \%$ & $3 \mathrm{wt} \%$ \\
\hline \multirow[t]{4}{*}{5} & Removal \% & 91.20 & 95.80 & 97.00 & 96.40 & 96.00 \\
\hline & $\sigma_{\text {removal } \%}$ & 1.58 & 1.66 & 1.68 & 1.67 & 1.66 \\
\hline & Efficiency \% & 29.66 & 37.87 & 45.29 & 46.32 & 50.12 \\
\hline & $\sigma_{\text {efficiency }} \%$ & 1.09 & 1.12 & 0.50 & 1.16 & 0.92 \\
\hline \multirow[t]{4}{*}{10} & Removal \% & 93.10 & 95.40 & 98.20 & 97.80 & 97.50 \\
\hline & $\sigma_{\text {removal }} \%$ & 1.23 & 1.26 & 1.00 & 1.29 & 1.29 \\
\hline & Efficiency $\%$ & 40.29 & 52.15 & 52.61 & 57.59 & 60.39 \\
\hline & $\sigma_{\text {efficiency }} \%$ & 0.81 & 0.67 & 0.39 & 0.49 & 0.23 \\
\hline \multirow[t]{4}{*}{20} & Removal \% & 86.00 & 90.85 & 96.40 & 96.15 & 92.15 \\
\hline & $\sigma_{\text {removal } \%}$ & 1.00 & 1.06 & 1.12 & 1.12 & 1.07 \\
\hline & Efficiency $\%$ & 70.66 & 76.54 & 79.45 & 83.80 & 85.21 \\
\hline & $\sigma_{\text {efficiency }} \%$ & 2.35 & 1.91 & 1.60 & 1.19 & 1.10 \\
\hline \multirow[t]{4}{*}{30} & Removal \% & 67.93 & 78.33 & 90.50 & 84.33 & 83.70 \\
\hline & $\sigma_{\text {removal }} \%$ & 1.79 & 2.06 & 2.38 & 2.22 & 2.20 \\
\hline & Efficiency $\%$ & 75.85 & 92.10 & 93.93 & 94.85 & 95.91 \\
\hline & $\sigma_{\text {efficiency }} \%$ & 0.89 & 0.40 & 0.49 & 0.41 & 0.21 \\
\hline \multirow[t]{4}{*}{50} & Removal \% & 40.54 & 46.80 & 50.36 & 46.28 & 45.60 \\
\hline & $\sigma_{\text {removal }} \%$ & 1.05 & 1.22 & 1.31 & 1.20 & 1.19 \\
\hline & Efficiency $\%$ & 90.61 & 96.24 & 97.79 & 98.41 & 99.09 \\
\hline & $\sigma_{\text {efficiency }} \%$ & 1.31 & 0.53 & 0.24 & 0.20 & 0.13 \\
\hline \multirow[t]{4}{*}{80} & Removal \% & 25.14 & 27.29 & 29.55 & 28.90 & 27.74 \\
\hline & $\sigma_{\text {removal } \%}$ & 1.20 & 1.19 & 1.56 & 2.56 & 3.05 \\
\hline & Efficiency $\%$ & 99.02 & 97.99 & 99.38 & 100.00 & 100.00 \\
\hline & $\sigma_{\text {efficiency }} \%$ & 0.24 & 0.48 & 0.13 & 0.00 & 0.00 \\
\hline
\end{tabular}

initial weight of oil by adsorbing up to $27.15 \mathrm{~g} / \mathrm{g}$ (i.e., $33.2 \%$ increase in oil sorption capacity $(\mathrm{g} / \mathrm{g})$ in comparison with the blank PUF sorption capacity of $20.38 \mathrm{~g} / \mathrm{g}$ ).
The maximum sorption capacity of the surface-modified PUF cubes and some other studied sorbents are reported in Table 3. The reported data reveal that the 
Table 3 Maximum oil sorption capacities of some sorbents reported in literature

\begin{tabular}{llll}
\hline Sorbent & Type of oil & Maximum sorption capacity $(\mathrm{g} / \mathrm{g})$ & References \\
\hline Carbonized pith bagasse & Gas oil & 25.5 & Hussein et al. (2008) \\
Natural wool fibers & Motor oil & 5.56 & Rajakovic et al. (2007) \\
Exfoliated graphite & Wasted engine oil & 13.2 & Tryba et al. (2003) \\
Nonwoven polypropylene & Light crude oil & 9 & Wei et al. (2003) \\
Macroporous organogel & Crude oil & 18.2 & Tuncaboylu and Okay (2009) \\
Blank PUF & Light crude oil & 20.38 & This study \\
1 wt\% MWCNT surface-modified PUF & Light crude oil & 27.15 & This study \\
\hline
\end{tabular}

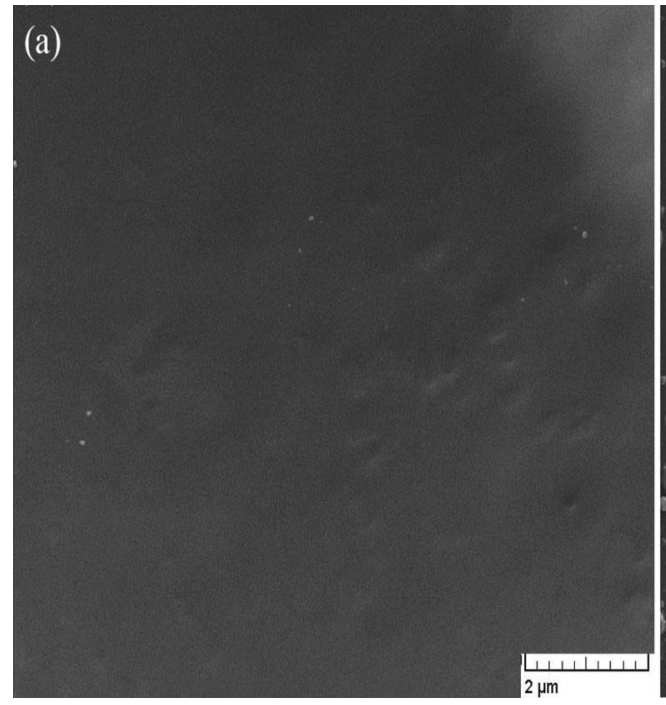

Fig. 4 SEM images of blank PUF $\mathbf{a}$ and AC surface-modified PUF b

surface-modified PUF cubes have noticeable oil sorption capacity compared with the other sorbents.

The oil removal increase in the case of surface-modified PUF may be explained by the fact that the AC presence on the PUF surface enhances the specific surface area of the PUF cubes which is directly related to the sorption capacity of the sorbent. According to the results of the tensile elongation test, one reason for the sorption increase may be the improvement of structural toughness which reduces the release of oil during the sorbent cubes removal from the polluted system. This is also inferred from the less shape reforming because of the gravitational force on the saturated cubes. According to the literature (Tanobe et al. 2009), another explanation for the adsorption capacity enhancement may be the increase in pores size which provides more space for the oil to be adsorbed. Similarly, Harikrishnan et al. (2006) and Wu et al. (2014) reported increase in the cells size after using nanoclays as the cell openers in the structure of the polyurethane foam and treating PUF sponges surface with $\mathrm{SiO}_{2}$ sol and gasoline, respectively. Moreover, another possible reason is the presence of the AC on the foam surface which is obvious by comparing the

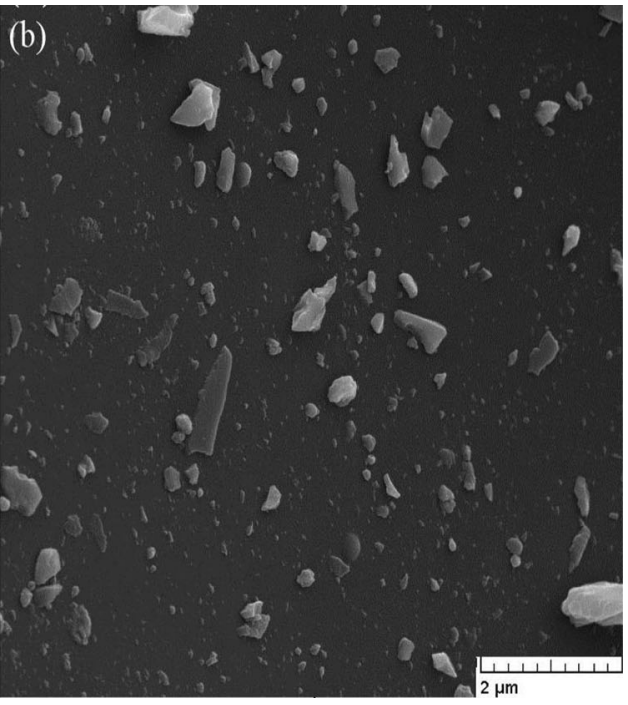

SEM images of the blank PUF (Fig. 4a) and AC surfacemodified PUF (Fig. 4b). The presence of the AC particles increases the roughness of surface which in turn helps the foam to hold the adsorbed oil as the physical configuration of the sorbent is an important property for adsorption and capillary action. The same phenomenon about the surface roughness was reported by (Choi and Moreau 1993) and (Radetic et al. 2003) in the case of polymeric sorbents such as polyester and recycled wool-based nonwoven material, respectively, especially in oil-rich environment.

\section{Oil removal efficiency}

The oil removal efficiency of the sorbents in different initial weight of oil is reported in Table 2. The reported data reveal a clear trend of efficiency improvement by oil initial weight increase. For each initial weight of oil, the efficiency is improved upon the increase in $\mathrm{AC}$ amount existing on the PUF surface and the sorbent with $3 \mathrm{wt} \%$ of AC has the maximum efficiency. The observed increase in oil removal efficiency can be attributed to the fact that on oil initial weight increase, the thickness of oil layer on the water 
Table 4 Sorbent removal percent, removal efficiency percent and their corresponding standard deviation $(\sigma)$ for the chemically regenerated $1 \mathrm{wt} \%$ MWCNT surface-modified PUF

\begin{tabular}{|c|c|c|c|c|c|}
\hline \multirow{2}{*}{$\begin{array}{l}\text { Initial amount } \\
\text { of oil }(\mathrm{g})\end{array}$} & \multirow{2}{*}{$\begin{array}{l}\text { Sorbent removal and } \\
\text { efficiency percent }\end{array}$} & \multicolumn{4}{|c|}{ Regeneration cycle } \\
\hline & & 1 & 2 & 3 & 4 \\
\hline \multirow[t]{4}{*}{5} & Removal \% & 97.00 & 93.40 & 91.20 & 89.40 \\
\hline & $\sigma_{\text {removal }} \%$ & 1.14 & 1.10 & 1.08 & 1.05 \\
\hline & Efficiency \% & 36.76 & 40.94 & 42.51 & 44.88 \\
\hline & $\sigma_{\text {efficiency }} \%$ & 1.48 & 1.54 & 1.56 & 1.57 \\
\hline \multirow[t]{4}{*}{10} & Removal \% & 98.70 & 97.20 & 90.80 & 88.60 \\
\hline & $\sigma_{\text {removal }} \%$ & 1.31 & 1.75 & 1.64 & 1.60 \\
\hline & Efficiency \% & 50.96 & 52.60 & 53.07 & 53.93 \\
\hline & $\sigma_{\text {efficiency }} \%$ & 0.57 & 0.21 & 0.21 & 0.21 \\
\hline \multirow[t]{4}{*}{20} & Removal \% & 99.25 & 97.50 & 96.55 & 91.40 \\
\hline & $\sigma_{\text {removal }} \%$ & 2.29 & 2.25 & 2.23 & 2.11 \\
\hline & Efficiency \% & 72.19 & 72.47 & 72.30 & 75.92 \\
\hline & $\sigma_{\text {efficiency }} \%$ & 0.39 & 0.39 & 0.39 & 0.35 \\
\hline \multirow[t]{4}{*}{30} & Removal \% & 83.67 & 80.77 & 79.60 & 76.67 \\
\hline & $\sigma_{\text {removal }} \%$ & 0.88 & 0.85 & 0.84 & 0.81 \\
\hline & Efficiency $\%$ & 89.90 & 90.75 & 91.71 & 94.85 \\
\hline & $\sigma_{\text {efficiency }} \%$ & 0.41 & 0.38 & 0.35 & 0.22 \\
\hline \multirow[t]{4}{*}{50} & Removal \% & 46.38 & 46.20 & 45.36 & 40.84 \\
\hline & $\sigma_{\text {removal }} \%$ & 0.81 & 0.81 & 0.79 & 0.71 \\
\hline & Efficiency \% & 95.67 & 97.51 & 98.68 & 99.28 \\
\hline & $\sigma_{\text {efficiency }} \%$ & 0.24 & 0.14 & 0.08 & 0.04 \\
\hline \multirow[t]{4}{*}{80} & Removal \% & 28.79 & 28.13 & 26.73 & 25.05 \\
\hline & $\sigma_{\text {removal }} \%$ & 0.52 & 0.51 & 0.48 & 0.45 \\
\hline & Efficiency $\%$ & 98.46 & 99.11 & 99.53 & 99.74 \\
\hline & $\sigma_{\text {efficiency }} \%$ & 2.67 & 1.54 & 0.82 & 0.44 \\
\hline
\end{tabular}

surface increases and the sorbent cubes reach the water surface to less extent, and therefore, the lower amount of water sorption enhances the efficiency. Another possible factor affecting the oil removal efficiency goes back to the surface modification by petroleum ether that improves the affinity toward oil. This explanation may be validated by the results obtained by Wu et al. (2014). Based on the results of contact angle test, they reported an improvement of hydrophobicity after treating PUF cubes with gasoline.

\section{Sorbents reusability}

Reusability feature of the $1 \mathrm{wt} \%$ AC surface-modified PUF has been investigated through four cycles of regeneration. The sorption and efficiency percentage of the regenerated sorbent are presented in Table 4. It is shown that for each initial weight of oil, the sorption percentage decreases which may be due to the incomplete regeneration of the sorbent. Incomplete regeneration stems from the permanent chemical sorption of some components on the surface which may not be released after chemical regeneration. Another reason for the decrease in sorption percentage may be loss of AC particle from the surface of foam, as the crude oil contains different types of organic and inorganic materials that adversely affect the bond between the AC particles and foam. As the data reported in Table 4 show, at each initial weight of oil, the sorption efficiency is increased. The increase in sorption efficiency may be explained by considering the regeneration method in which the sorbents are regenerated by petroleum ether, meaning even after drying, some petroleum ether remained on the surface and this, besides the remained crude oil, increases the affinity for the oil; thus, less water is adsorbed which in turn enhances the sorption efficiency.

\section{Adsorption isotherms}

The parameters of the isotherm models obtained from the linear regression method and the values of $R^{2}$, HYBRID and MPSD are reported in Table 5. The values of $R^{2}$, reported in Table 5, for the Freundlich isotherm in comparison with the values for Langmuir and Redlich-Peterson suggest that it is not an appropriate model for the prediction of sorption of crude oil onto PUF. Moreover, ranking the Langmuir and Redlich-Peterson models on the basis of the $R^{2}$ values seems to be inaccurate as the obtained values of $R^{2}$ are too close to each other without considering degrees of freedom. Ranking the models based on the values of HYBRID and 
Table 5 Predicted parameters of Langmuir, Redlich-Peterson and Freundlich isotherm by linear regression method

\begin{tabular}{|c|c|c|c|c|c|}
\hline Isotherm & Blank PUF & $\begin{array}{l}0.5 \mathrm{wt} \% \text { AC surface- } \\
\text { modified PUF }\end{array}$ & $\begin{array}{l}1 \mathrm{wt} \% \text { AC surface- } \\
\text { modified PUF }\end{array}$ & $\begin{array}{l}2 \mathrm{wt} \% \text { AC surface- } \\
\text { modified PUF }\end{array}$ & $\begin{array}{l}3 \mathrm{wt} \% \text { AC surface- } \\
\text { modified PUF }\end{array}$ \\
\hline \multicolumn{6}{|l|}{ Langmuir } \\
\hline$q_{\mathrm{m}}\left(\mathrm{g} \mathrm{g}^{-1}\right)$ & 20.4499 & 22.17295 & 23.8663 & 23.2558 & 22.3713 \\
\hline$K_{\mathrm{L}}\left(\mathrm{Lg}^{-1}\right)$ & 1.4215 & 6.5362 & 5.58 & 5.1807 & 6.9844 \\
\hline$R^{2}$ & 0.9995 & 0.9985 & 0.9993 & 0.9998 & 0.9995 \\
\hline HYBRID & 65.1501 & 482.1056 & 209.8682 & 239.1541 & 422.2948 \\
\hline MPSD & 36.7824 & 92.1263 & 62.7966 & 68.0075 & 89.2653 \\
\hline \multicolumn{6}{|l|}{ Redlich-Peterson } \\
\hline$g$ & 1.035 & 0.99 & 1.195 & 1.09 & 1.05 \\
\hline$K_{\mathrm{R}}\left(L g^{-1}\right)$ & 20.2024 & 21.0084 & 24.2130 & 23.4192 & 23.3645 \\
\hline$a_{\mathrm{R}}\left(\mathrm{L} g_{\mathrm{R}}^{1-1 / K}\right)$ & 0.8545 & 1.0210 & 0.4866 & 0.7283 & 0.8171 \\
\hline$R^{2}$ & 0.9998 & 0.9968 & 0.9992 & 0.9993 & 0.9993 \\
\hline HYBRID & 31.3523 & 134.5501 & 253.9653 & 214.9102 & 114.9809 \\
\hline MPSD & 25.1785 & 31.2228 & 48.4838 & 41.0989 & 32.2954 \\
\hline \multicolumn{6}{|l|}{ Freundlich } \\
\hline$K_{\mathrm{F}}\left(\mathrm{g} \mathrm{g}^{-1}\right)(\mathrm{L} / \mathrm{g})^{n}$ & 13.6576 & 10.7263 & 11.2909 & 12.5221 & 11.6744 \\
\hline$n$ & 1.8661 & 3.9825 & 6.1012 & 4.655493 & 4.3706 \\
\hline$R^{2}$ & 0.8001 & 0.7525 & 0.7439 & 0.6349 & 0.6858 \\
\hline HYBRID & $1.55 \mathrm{E}+10$ & 193.2091 & 378.8958 & 263.9201 & 235.2566 \\
\hline MPSD & $277,584.5$ & 37.8665 & 51.3192 & 49.4735 & 44.6967 \\
\hline
\end{tabular}

MPSD suggests that Langmuir, Redlich-Peterson and Freundlich are the best fits to the experimental data.

In the case of nonlinear regression method, the calculated isotherm parameters, the corresponding error functions and SNEs for the minimum error distribution between the experimental equilibrium data and predicted isotherm are presented in Table 6. The bolded numbers in each column in Table 6 show the minimum of the SNEs, meaning the parameters obtained by minimization of that error are the most appropriate ones. For example, the best calculated parameters of the Langmuir isotherm in the case of blank PUF are the ones obtained by minimization of the SSE. It is obvious that the Langmuir model is the more appropriate model for explaining the saturation limitation of the sorption process. The reported data in Tables 5 and 6 reveal that the value of $g$ for the RedlichPeterson model is more than 1 in all cases. The exponent higher than one may be explained by the fact that the prominent mechanism of sorption of the foam-based sorbents is the capillary action.

As the fitted models have different numbers of parameters (Langmuir and Freundlich: 2; Redlich-Peterson: 3), ranking the isotherms is performed based on the values of MPSD and HYBRID error functions. Comparing the values of the MPSD and HYBRID error measurement reveals that the quality of the isotherm fit can be arranged in order of increasing weight of the errors as: Redlich-Peterson $<$ Langmuir $<$ Freundlich for the blank and $0.5 \mathrm{wt} \%$
AC surface-modified PUF and Langmuir $<$ RedlichPeterson $<$ Freundlich for the 1, 2 and $3 \mathrm{wt} \%$ AC surfacemodified PUF. The reason to the change in ranking between Langmuir and Redlich-Peterson model may be explained by the little change in sorption mechanism after addition of AC particle to the surface of PUF. As previously stated, the prominent mechanism of sorption in the foams is capillary action; however, on the increase in AC particle concentration on the surface, the monolayer sorption (the main assumption of the Langmuir isotherm) on the surface of the AC particles and the PUF surface affect the sorption mechanism.

A comparison of the curves of the equilibrium data with the classification proposed by (Giles et al. 1960) indicates the similarity of the L curves and the depicted curves of the present study. The L curves are the best-known pattern of sorption data, and the initial curvature shows that as the more sites are occupied, it becomes difficult for the other molecules to find free sites and that the adsorbed molecules are probably adsorbed flat.

\section{Conclusion}

The impregnation of the PUF has been performed through the reaction of the chemical groups existing on the surface of $\mathrm{AC}$ particles and those belonging to the unreacted PUF polyol with MDI functionalities. The experimental 
Table 6 Predicted parameters of Langmuir, Redlich-Peterson and Freundlich isotherm by nonlinear regression method through minimizing the HYBRID and MPSD error functions

\begin{tabular}{|c|c|c|c|c|c|}
\hline Isotherm & Blank PUF & $\begin{array}{l}0.5 \mathrm{wt} \% \text { AC surface- } \\
\text { modified PUF }\end{array}$ & $\begin{array}{l}1 \mathrm{wt} \% \text { AC surface- } \\
\text { modified PUF }\end{array}$ & $\begin{array}{l}2 \mathrm{wt} \% \text { AC surface- } \\
\text { modified PUF }\end{array}$ & $\begin{array}{l}3 \mathrm{wt} \% \text { AC surface- } \\
\text { modified PUF }\end{array}$ \\
\hline \multicolumn{6}{|l|}{ Langmuir } \\
\hline$q_{\mathrm{m}}\left(\mathrm{g} \mathrm{g}^{-1}\right)$ & 20.38 & 23.5 & 26.38503 & 25.08328 & 24.24982 \\
\hline$K_{\mathrm{L}}\left(\mathrm{Lg}^{-1}\right)$ & 0.95742 & 1.441049 & 2.589171 & 2.139087 & 1.796086 \\
\hline HYBRID & 29.28886 & 12.13017 & 93.73207 & 60.89002 & 42.5577 \\
\hline Sum of normalized HYBRID & 6.470238 & 7.260028 & 5.735964 & 6.099829 & 5.805036 \\
\hline$q_{\mathrm{m}}\left(\mathrm{g} \mathrm{g}^{-1}\right)$ & 20.38 & 23.5 & 26.64115 & 25.3 & 24.49424 \\
\hline$K_{\mathrm{L}}\left(\mathrm{Lg}^{-1}\right)$ & 0.820633 & 1.341253 & 2.031706 & 1.732866 & 1.53379 \\
\hline MPSD & 17.48253 & 8.855496 & 30.67121 & 23.9068 & 20.32865 \\
\hline Sum of normalized MPSD & 6.271849 & 6.685061 & 5.767429 & 6.159723 & 6.274002 \\
\hline \multicolumn{6}{|l|}{ Redlich-Peterson } \\
\hline $\mathrm{g}$ & 1.108433 & 1.112438 & 1.236579 & 1.205715 & 1.147492 \\
\hline$K_{\mathrm{R}}\left(\mathrm{L}^{-1}\right)$ & 15.03223 & 23.5 & 27.15 & 25.3 & 25.1 \\
\hline$a_{\mathrm{R}}\left(\mathrm{L} g_{\mathrm{R}}^{1-1 / K}\right)$ & 0.481097 & 0.673704 & 0.463631 & 0.512426 & 0.633087 \\
\hline HYBRID & 15.92245 & 5.869236 & 199.1734 & 133.4575 & 62.84631 \\
\hline Sum of normalized HYBRID & 6.312063 & 7.836284 & 4.710827 & 2.564682 & 7.328421 \\
\hline $\mathrm{g}$ & 1.136828 & 1.12646 & 1.259608 & 1.235422 & 1.162458 \\
\hline$K_{\mathrm{R}}\left(\mathrm{Lg}^{-1}\right)$ & 13.53567 & 23.5 & 27.15 & 25.3 & 25.1 \\
\hline$a_{\mathrm{R}}\left(\mathrm{L} g_{\mathrm{R}}^{1-1 / K}\right)$ & 0.389818 & 0.644229 & 0.428448 & 0.465083 & 0.603691 \\
\hline MPSD & 14.42758 & 8.103472 & 43.19673 & 32.67488 & 25.13489 \\
\hline Sum of normalized MPSD & 2.814804 & 3.691628 & 2.62146 & 2.434915 & 4.161529 \\
\hline \multicolumn{6}{|l|}{ Freundlich } \\
\hline$K_{\mathrm{F}}\left(\mathrm{g} \mathrm{g}^{-1}\right)(\mathrm{L} / \mathrm{g})^{n}$ & 9.010921 & 10.8895 & 13.01478 & 12.06515 & 11.51052 \\
\hline$n$ & 4.248957 & 4.588896 & 5.230367 & 5.035781 & 4.897463 \\
\hline HYBRID & 141.8959 & 170.8041 & 298.5617 & 247.6416 & 215.8103 \\
\hline Sum of normalized HYBRID & 2.239558 & 2.174227 & 3.683705 & 3.372295 & 3.513399 \\
\hline$K_{\mathrm{F}}\left(\mathrm{g} \mathrm{g}^{-1}\right)(\mathrm{L} / \mathrm{g})^{n}$ & 7.561714 & 9.338805 & 10.71831 & 10.05669 & 9.683561 \\
\hline$n$ & 3.502567 & 3.814125 & 4.138535 & 4.026093 & 3.975359 \\
\hline MPSD & 34.18453 & 34.29186 & 44.85461 & 41.42543 & 38.86507 \\
\hline Sum of normalized MPSD & 3.159314 & 3.00494 & 4.308983 & 6.36899 & 4.954346 \\
\hline
\end{tabular}

data have shown that the presence of $1 \mathrm{wt} \%$ of $\mathrm{AC}$ on the surface of PUF increases the sorption capacity up to $33.2 \%$ in comparison with the blank PUF. Furthermore, the sorption efficiency has increased in all amount of AC on the surface of PUF as less water and more oil have been adsorbed. The reusability feature of the $1 \mathrm{wt} \% \mathrm{AC}$ surface-modified sorbent has been investigated through four cycles of chemical regeneration and reuse. The investigation of the best-fitting isotherm model through minimization of various error functions using linear method has proposed the Langmuir as the best fit, while the nonlinear method has suggested that for the blank and the $0.5 \mathrm{wt} \%$ surface-modified PUFs, Redlich-Peterson is the best fit while for the 1, 2 and $3 \mathrm{wt} \%$ surface-modified PUFs, the Langmuir model is the best fit of the sorption data.
Acknowledgments Financial support from Iranian Oil Terminals Company (Grant Number: pzh/92-038-100-0009) is highly appreciated.

\section{References}

Adebajo MO, Frost RL, Kloprogge JT, Carmody O, Kokot S (2003) Porous materials for oil spill cleanup: a review of synthesis and absorbing properties. J Porous Mater 10:159-170

Aguilera F, Méndez J, Pásaro E, Laffon B (2010) Review on the effects of exposure to spilled oils on human health. J Appl Toxicol 30:291-301

Al-Majed AA, Adebayo AR, Hossain ME (2012) A sustainable approach to controlling oil spills. J Environ Manage 113:213-227

Alves P, Coelho JFJ, Haack J, Rota A, Bruinink A, Gil MH (2009) Surface modification and characterization of thermoplastic polyurethane. Eur Polym J 45:1412-1419 
Annunciado T, Sydenstricker T, Amico S (2005) Experimental investigation of various vegetable fibers as sorbent materials for oil spills. Mar Pollut Bull 50:1340-1346

Avila AF, Munhoz VC, de Oliveira AM, Santos MCG, Lacerda GRBS, Gonçalves CP (2014) Nano-based systems for oil spills control and cleanup. J Hazard Mater 272:20-27

Banerjee SS, Joshi MV, Jayaram RV (2006) Treatment of oil spill by sorption technique using fatty acid grafted sawdust. Chemosphere 64:1026-1031

Bhatnagar A, Hogland W, Marques M, Sillanpää M (2013) An overview of the modification methods of activated carbon for its water treatment applications. Chem Eng J 219:499-511

Choi HM, Moreau JP (1993) Oil sorption behavior of various sorbents studied by sorption capacity measurement and environmental scanning electron microscopy. Microsc Res Tech 25:447-455

El-Khaiary MI, Malash GF (2011) Common data analysis errors in batch adsorption studies. Hydrometallurgy 105:314-320

Emam EA (2013) Modified activated carbon and bentonite used to adsorb petroleum hydrocarbons emulsified in aqueous solution. Am J Environ Prot 2:161-169

Foo K, Hameed B (2010) Insights into the modeling of adsorption isotherm systems. Chem Eng J 156:2-10

Giles CH, MacEwan TH, Nakhwa SN, Smith D (1960) Studies in adsorption. Part XI. A system of classification of solution adsorption isotherms, and its use in diagnosis of adsorption mechanisms and in measurement of specific surface areas of solids. J Chem Soc 60:3973-3993

Hamdaoui O, Naffrechoux E (2007) Modeling of adsorption isotherms of phenol and chlorophenols onto granular activated carbon: part II. Models with more than two parameters. J Hazard Mater 147:401-411

Harikrishnan G, Patro TU, Khakhar D (2006) Polyurethane foamclay nanocomposites: nanoclays as cell openers. Ind Eng Chem Res 45:7126-7134

Ho Y-S (2006) Isotherms for the sorption of lead onto peat: comparison of linear and non-linear methods. Pol J Environ Stud 15:81-86

Ho Y, Porter J, McKay G (2002) Equilibrium isotherm studies for the sorption of divalent metal ions onto peat: copper, nickel and lead single component systems. Water Air Soil Pollut 141:1-33

Ho Y-S, Chiu W-T, Wang C-C (2005) Regression analysis for the sorption isotherms of basic dyes on sugarcane dust. Bioresour Technol 96:1285-1291

Hussein M, Amer AA, Sawsan II (2008) Oil spill sorption using carbonized pith bagasse: 1. Preparation and characterization of carbonized pith bagasse. J Anal Appl Pyrol 82:205-211

Kumar KV, Porkodi K, Rocha F (2008) Comparison of various error functions in predicting the optimum isotherm by linear and nonlinear regression analysis for the sorption of basic red 9 by activated carbon. J Hazard Mater 150:158-165

Langmuir I (1918) The adsorption of gases on plane surfaces of glass, mica and platinum. J Am Chem Soc 40:1361-1403

Li H, Liu L, Yang F (2012) Hydrophobic modification of polyurethane foam for oil spill cleanup. Mar Pollut Bull 64:1648-1653

Limousin G, Gaudet JP, Charlet L, Szenknect S, Barthès V, Krimissa M (2007) Sorption isotherms: a review on physical bases, modeling and measurement. Appl Geochem 22:249-275

Marsh H, Reinoso FR (2006) Activated carbon. Elsevier, Amsterdam

Najafi M, Rostamian R, Rafati AA (2011) Chemically modified silica gel with thiol group as an adsorbent for retention of some toxic soft metal ions from water and industrial effluent. Chem Eng J 168:426-432

Ncibi MC (2008) Applicability of some statistical tools to predict optimum adsorption isotherm after linear and non-linear regression analysis. J Hazard Mater 153:207-212

$\mathrm{Ng} \mathrm{J}$, Cheung W, McKay G (2002) Equilibrium studies of the sorption of $\mathrm{Cu}$ (II) ions onto chitosan. J Colloid Interf Sci 255:64-74
Okiel K, El-Sayed M, El-Kady MY (2011) Treatment of oil-water emulsions by adsorption onto activated carbon, bentonite and deposited carbon. Egypt J Petroleum 20:9-15

Pal MK, Gautam J (2013) Effects of inorganic nanofillers on the thermal degradation and UV-absorbance properties of polyvinyl acetate. J Therm Anal Calorim 111:689-701

Radetic MM, Jocic DM, Jovancic PM, Petrovic ZL, Thomas HF (2003) Recycled wool-based nonwoven material as an oil sorbent. Environ Sci Technol 37:1008-1012

Radhika M, Palanivelu K (2006) Adsorptive removal of chlorophenols from aqueous solution by low cost adsorbent-kinetics and isotherm analysis. J Hazard Mater 138:116-124

Rajakovic V, Aleksic G, Radetic M, Rajakovic L (2007) Efficiency of oil removal from real wastewater with different sorbent materials. J Hazard Mater 143:494-499

Rivera-Utrilla J, Sánchez-Polo M, Gómez-Serrano V, Álvarez PM, Alvim-Ferraz MCM, Dias JM (2011) Activated carbon modifications to enhance its water treatment applications. An overview. J Hazard Mater 187:1-23

Said AE-AA, Ludwick AG, Aglan HA (2009) Usefulness of raw bagasse for oil absorption: a comparison of raw and acylated bagasse and their components. Bioresour Technol 100:2219-2222

Shafeeyan MS, Daud WMAW, Houshmand A, Shamiri A (2010) A review on surface modification of activated carbon for carbon dioxide adsorption. J Anal Appl Pyrol 89:143-151

Sidik SM, Jalil AA, Triwahyono S, Adam SH, Satar MAH, Hameed BH (2012) Modified oil palm leaves adsorbent with enhanced hydrophobicity for crude oil removal. Chem Eng J 203:9-18

Tanobe VOA, Sydenstricker THD, Amico SC, Vargas JVC, Zawadzki SF (2009) Evaluation of flexible postconsumed polyurethane foams modified by polystyrene grafting as sorbent material for oil spills. J Appl Polym Sci 111:1842-1849

Teas C, Kalligeros S, Zanikos F, Stournas S, Lois E, Anastopoulos G (2001) Investigation of the effectiveness of absorbent materials in oil spills clean up. Desalination 140:259-264

Tryba B, Morawski AW, Kaleńczuk RJ, Inagaki M (2003) Exfoliated graphite as a new sorbent for removal of engine oils from wastewater. Spill Sci Technol Bull 8:569-571

Tuncaboylu DC, Okay O (2009) Preparation and characterization of single-hole macroporous organogel particles of high toughness and superfast responsivity. Eur Polym J 45:2033-2042

Vargas AMM, Cazetta AL, Kunita MH, Silva TL, Almeida VC (2011) Adsorption of methylene blue on activated carbon produced from flamboyant pods (Delonix regia): study of adsorption isotherms and kinetic models. Chem Eng J 168:722-730

Vasanth kumar K, Sivanesan S (2006) Equilibrium data, isotherm parameters and process design for partial and complete isotherm of methylene blue onto activated carbon. J Hazard Mater 134:237-244

Wei Q, Mather R, Fotheringham A, Yang R (2003) Evaluation of nonwoven polypropylene oil sorbents in marine oil-spill recovery. Mar Pollut Bull 46:780-783

Wu F-C, Liu B-L, Wu K-T, Tseng R-L (2010) A new linear form analysis of Redlich-Peterson isotherm equation for the adsorptions of dyes. Chem Eng J 162:21-27

Wu D, Fang L, Qin Y, Wu W, Mao C, Zhu H (2014) Oil sorbents with high sorption capacity, oil/water selectivity and reusability for oil spill cleanup. Mar Pollut Bull 84:263-267

Yin CY, Aroua MK, Daud WMAW (2007) Review of modifications of activated carbon for enhancing contaminant uptakes from aqueous solutions. Sep Purif Technol 52:403-415

Zhou Y-B, Tang X-Y, Hu X-M, Fritschi S, Lu J (2008) Emulsified oily wastewater treatment using a hybrid-modified resin and activated carbon system. Sep Purif Technol 63:400-406 